\title{
Efficiency of a Regenerative Direct-Drive Electromagnetic Active Suspension
}

\author{
Bart L. J. Gysen, Member, IEEE, Tom P. J. van der Sande, Johannes J. H. Paulides, Member, IEEE, and \\ Elena A. Lomonova, Fellow, IEEE
}

\begin{abstract}
The efficiency and power consumption of a direct-drive electromagnetic active suspension system for automotive applications are investigated. A McPherson suspension system is considered, where the strut consists of a direct-drive brushless tubular permanent-magnet actuator in parallel with a passive spring and damper. This suspension system can both deliver active forces and regenerate power due to imposed movements. A linear quadratic regulator controller is developed for the improvement of comfort and handling (dynamic tire load). The power consumption is simulated as a function of the passive damping in the active suspension system. Finally, measurements are performed on a quarter-car test setup to validate the analysis and simulations.
\end{abstract}

Index Terms-Active suspension, permanent magnet actuator, quarter car .

\section{INTRODUCTION}

$\mathbf{T}$ HE CURRENT and future trend in the automotive industry is toward commercializing hybrid electric vehicles (HEVs) and full electric vehicles. An example in this trend is the in-wheel motor, which has high performance, increased efficiency, an absence of mechanical gears, flexibility, and less space requirements at the sprung mass for the placement of, for example, a battery pack [1]. Aside from all the improvements, this technology has a major drawback, and it is shown that the comfort and stability drastically decreases due to the increase in unsprung-to-sprung mass ratio [2]. Although in-wheel motors allow the degree of freedom to independently control traction and brake forces [3], the improvement of comfort is extremely difficult. Therefore, an active suspension system will be necessary for the successful implementation of these systems.

Electromagnetic active suspension systems increasingly become attractive replacements for the currently installed passive, semiactive, and hydraulic active suspension systems due to the their efficiency and decreasing costs [4], [5]. Research has proven that the limited force density of an electromagnetic system, compared with a hydraulic system, can be overcome by the proper choice of design, materials, and geometrical optimization, resulting in a relatively high force density of 663

\footnotetext{
Manuscript received November 16, 2010; revised February 11, 2011; accepted March 10, 2011. Date of publication March 22, 2011; date of current version May 16, 2011. This work was supported by Svenska Kullagerfabriken (SKF). The review of this paper was coordinated by Prof. A. Emadi.

The authors are with the Department of Electrical Engineering, Eindhoven University of Technology, 5600MB Eindhoven, The Netherlands (e-mail: b.1.j. gysen@tue.nl).

Color versions of one or more of the figures in this paper are available online at http://ieeexplore.ieee.org.

Digital Object Identifier 10.1109/TVT.2011.2131160
}

$\mathrm{kN} / \mathrm{m}^{3}$ [6]. In addition, the ability of regeneration, although limited [7], makes these systems more suitable due to the importance of reduced $\mathrm{CO}_{2}$ emissions. Due to the development toward HEVs, electromagnetic suspension systems are easier to implement, because HEVs have their own energy storage system, which controls the peak power demand and regenerative power of the active suspension system [8]. Finally, these systems offer an increased bandwidth of about a factor 10 , relative to hydraulics and pneumatics, which drastically improves the performance with regard to the comfort, stability, and flexibility of full vehicle control. This paper investigates the efficiency and power consumption of a direct-drive electromagnetic active suspension system, as shown in Fig. 1, which consists of a coil spring in parallel with a brushless tubular permanent-magnet actuator (TPMA) [2], [6 ], [9]-[12]. Due to its high force density, ideally zero attraction force, tubular structure, and the absence of mechanical gearbox, the system is an excellent candidate for providing active forces within a very short response time. Furthermore, it can directly transfer linear motion into electrical energy, decreasing the overall energy consumption. In Section II, the topology and specifications of the electromagnetic suspension system are given, together with the performance data of the developed prototype for a BMW 530i, as shown in Fig. 2. The modeling and control design for the comfort and handling objective is discussed in Section III. Initially, the amount of passive damping in the active suspension is considered a variable, and a linear quadratic regulator (LQR) controller is developed for the given specifications, depending on the amount of passive damping. Section IV shows the simulation results for all the criteria, giving an overview of the overall power consumption and efficiency. Measurements on a quarter-car test setup, including the prototype active suspension system, prove the simulated performance and indicate the power consumption for comfort and handling settings. Finally, conclusions are drawn in Section V.

\section{ELECTROMAGNETIC SuSPENSION SySTEM}

The volumetric specifications of the electromagnetic suspension system are taken such that a retro fit on a BMW 530i is possible. The passive strut of the McPherson suspension will be replaced by the electromagnetic suspension system shown in Figs. 1 and 2 . It consists of a passive coil spring to support the sprung mass and a direct-drive brushless TPMA to deliver active forces. With regard to safety, the suspension system should provide damping when a power breakdown occurs; hence, a passive damper $d_{p}$ should be incorporated into the active suspension system. This condition can be obtained through an oil-filled 


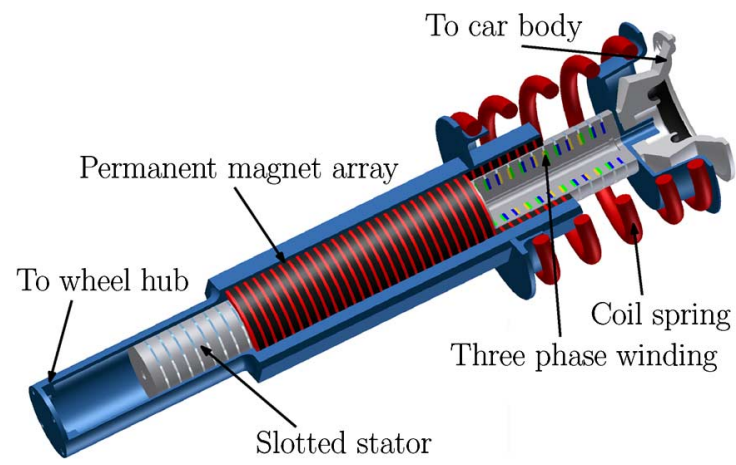

Fig. 1. Direct-drive electromagnetic active suspension system.

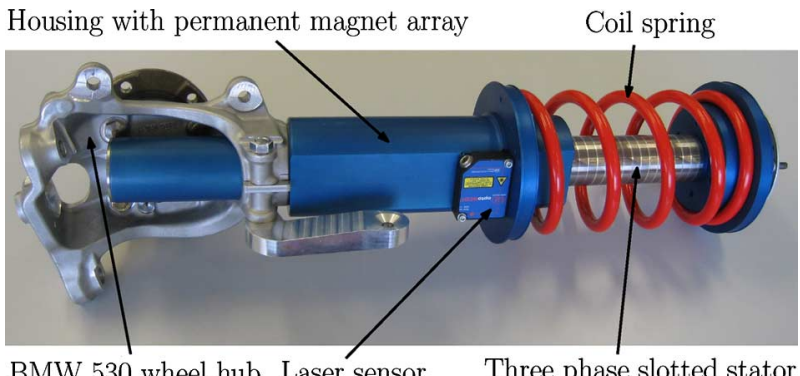

BMW 530 wheel hub Laser sensor

Three phase slotted stator

Fig. 2. Prototype of the electromagnetic active suspension system for a BMW 530i together with the wheel hub.

damper in parallel; however, because an electromagnetic actuator is considered, it is obtained through eddy currents that are induced in the conducting unlaminated stator.

The question is what the amount of passive damping should have an efficient system, given certain specifications for comfort, tire load, and suspension travel. In general, lower passive damping will increase the ability of regenerating power, because the actuator has to perform the "damping" function; however, the safety decreases, because less passive damping is present when a power breakdown occurs. Therefore, during the initial analysis, the amount of passive damping will be considered a variable, and the influence on the performance and power consumption will be analyzed.

This suspension system was already optimized and designed in [6], resulting in the TPMA having the permanent magnets (PMs) on the outer tube and a three-phase slotted stator as the inner tube. The PM array is attached to the wheel hub through an aluminum housing, as shown in Fig. 1. The slotted stator with a three-phase winding topology is attached to the car body; hence, moving wires are avoided. The actuator is designed for minimal copper losses for a mean output force of $1 \mathrm{kN}$. The parameters of the constructed prototype are summarized in Table I. The force-current dependency is shown in Fig. 3 , together with the approximated motor constant of 115 N/A, which is valid up to $2100 \mathrm{~N}$. The $12-\mathrm{V}$ battery of common passenger cars is not considered a limit, because the development in the automotive industry is toward higher voltage levels, particularly in HEVs and full electric vehicles. The actuator will be
TABLE I

PARAMETERS OF THE TPMA

\begin{tabular}{|c||c||c|}
\hline Parameter & Value & Description \\
\hline$R_{p h}$ & $1.7 \Omega$ & Phase resistance \\
\hline$L_{p h}$ & $10 \mathrm{mH}$ & Phase inductance \\
\hline$K_{i}$ & $115 \mathrm{~N} / \mathrm{A}$ & Motor constant up to $F_{\text {act }}=2100 \mathrm{~N}$ \\
\hline$K_{e}$ & $76.6 \mathrm{Vs} / \mathrm{m}$ & EMF constant \\
\hline$F_{R M S}$ & $1 \mathrm{kN}$ & RMS force \\
\hline$F_{\text {peak }}$ & $2.5 \mathrm{kN}$ & Peak force \\
\hline$z_{\text {max }}$ & $80 \mathrm{~mm}$ & Maximum rebound stroke \\
\hline$z_{\min }$ & $60 \mathrm{~mm}$ & Maximum bound stroke \\
\hline$\tau_{p}$ & $7.7 \mathrm{~mm}$ & Magnetic pole pitch \\
\hline
\end{tabular}

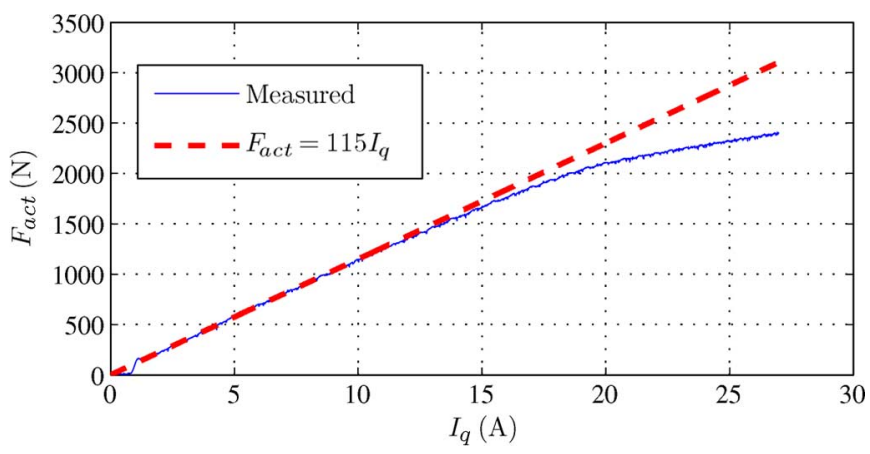

Fig. 3. Measured active force as function of the quadrature current of the electromagnetic active suspension system.

driven by a pulsewidth modulation (PWM) current-controlled three-phase amplifier with a dc bus voltage level of $340 \mathrm{~V} \mathrm{(} \pm$ $170 \mathrm{~V}$ ), a switching frequency of $20 \mathrm{kHz}$, and a current control loop bandwidth of $3 \mathrm{kHz}$. Hence, with an electromotive force (EMF) constant $K_{e}$ of $76.6 \mathrm{Vs} / \mathrm{m}$, the speed $v$ could reach up to $2.21 \mathrm{~m} / \mathrm{s}$, which is far beyond the maximum speeds that occur in the suspension system [2]. The amplifier can provide a three-phase current $i_{p h}$ of a 30-A root mean square (rms) and a 60-A peak. The axial output force of the actuator will be modeled as $F_{a c t}=K_{i} I_{q}$, where $I_{q}$ is the amplitude of the three-phase commutated quadrature current $i_{p h}$ given by

$$
\begin{aligned}
& i_{a}=I_{q} \cos \left(\frac{\pi z}{\tau_{p}}+\phi\right) \\
& i_{b}=I_{q} \cos \left(\frac{\pi z}{\tau_{p}}+\frac{2 \pi}{3}+\phi\right) \\
& i_{c}=I_{q} \cos \left(\frac{\pi z}{\tau_{p}}+\frac{4 \pi}{3}+\phi\right)
\end{aligned}
$$

for phases $\mathrm{a}, \mathrm{b}$ and $\mathrm{c}$, respectively, with $\phi$ being the commutation angle and $\tau_{p}$ being the pole pitch of the quasi Halbach PM array. Because the scope of this paper is on the average power levels of the active suspension strut, an ideal amplifier is assumed with an ideal current control. One phase leg of the circuit diagram is shown in Fig. 4, and the associated equations for the copper 
losses $P_{c u}$, mechanical power $P_{m e}$, and supply power $P_{s}$ are given by

$$
\begin{aligned}
P_{c u} & =\frac{1}{t_{e}} \sum_{p h}^{a, b, c} \int_{0}^{t_{e}} R_{p h} i_{p h}^{2} d t \\
P_{m e} & =\frac{1}{t_{e}} \int_{0}^{t_{e}} F_{a c t} v d t \\
P_{s} & =\frac{1}{t_{e}} \sum_{p h}^{a, b, c} \int_{0}^{t_{e}} V_{p h} i_{p h} d t \\
V_{p h} & =i_{p h} R_{p h}+L_{p h} \frac{\delta i_{p h}}{\delta t}+K_{e} v
\end{aligned}
$$

with $t_{e}$ being the simulation length, which is set to $30 \mathrm{~s}$. Inherently, the TPMA will have eddy current losses, which will result in damping forces $F_{d}$; however, these forces are not considered "losses," because they contribute to the value of the passive damping $d_{p}$. Because the suspension system can work in four quadrant operations, the passive damping $d_{p}$ can be decreased (motor mode) and increased (generator mode) by applying active forces (see Fig. 5). The efficiency of an electromechanical servo system is generally defined as the ratio between the effective delivered mechanical power and the total input power. However, for an electromagnetic suspension system that works in four quadrant operations, the mechanical output power is not necessarily "effective" or "useful" output power. The following different cases have to be considered.

- $P_{m e}<0$ and $P_{s}<0$. The actuator works in the generator mode and partially delivers power to the dc bus; hence, the efficiency is defined as follows: $\eta=\left(P_{s} / P_{m e}\right)$.

- $P_{m e}>0$ and $P_{s}>0$. The actuator works in the motor mode, and the dc bus partially delivers power to the actuator; hence, the efficiency is defined as follows: $\eta=$ $-\left(P_{m e} / P_{s}\right)$. The efficiency is defined negative, because energy is delivered by the battery.

- $P_{m e}<0$ and $P_{s}>0$. The actuator works in the generator mode, and the dc bus delivers power. This situation occurs when extreme damping is necessary. The regenerated power and the supply power are dissipated as copper losses; hence, the efficiency is zero.

- $P_{m e}>0$, and $P_{s}<0$. This situation never occurs.

Hence, overall, a positive value of $\eta$ gives the efficiency of regenerated power from the active suspension system, whereas a negative value of $\eta$ gives the efficiency in which electrical energy is converted into mechanical energy for the active suspension system. Although the use of PMs results in a system with high performance and efficiency, it makes the system expensive and dependent on the availability of rare-earth materials. Future research is necessary in reducing the amount of rare-earth materials, e.g., replacing the PMs by electromagnets. However, this approach drops the fail-safe functioning of the active suspension system. Investigation of different topologies, e.g., tubular induction or tubular flux switching actuators, is given in [11] ; however, it is concluded that these topologies do not provide the necessary force density that PM topologies can offer.

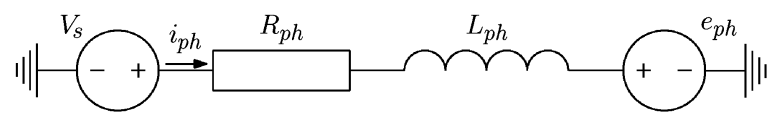

Fig. 4. Circuit diagram of one phase leg.

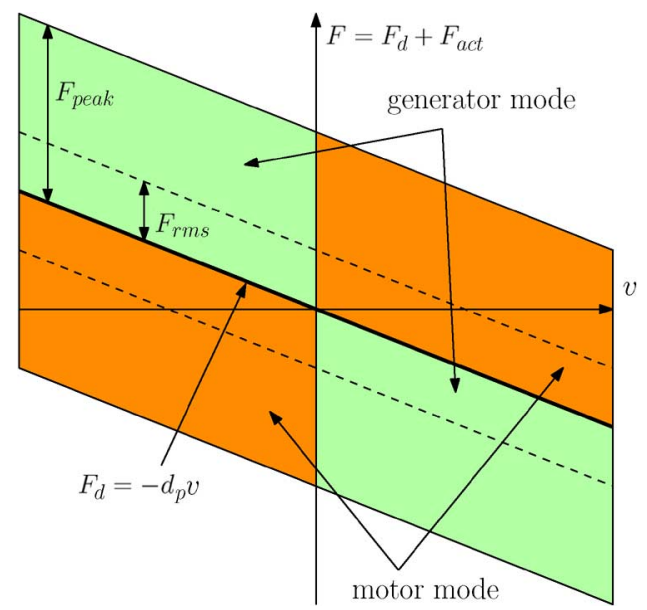

Fig. 5. Force velocity characteristic with various modes of operation.

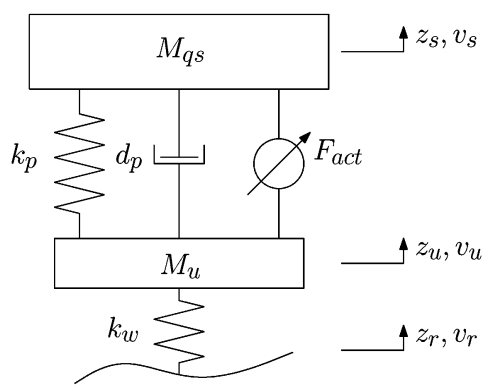

Fig. 6. Quarter-car model.

TABLE II

PARAMETERS OF THE BMW 530I

\begin{tabular}{|c||c||c|}
\hline Parameter & Value & Description \\
\hline$M_{s}$ & $1500 \mathrm{~kg}$ & Sprung mass \\
\hline$M_{u}$ & $45 \mathrm{~kg}$ & Unprung mass \\
\hline$k_{p}$ & $30 \mathrm{~N} / \mathrm{mm}$ & Coil spring stiffness \\
\hline$k_{w}$ & $350 \mathrm{~N} / \mathrm{mm}$ & Tire stiffness \\
\hline
\end{tabular}

\section{Modeling AND Control Design}

A quarter-car model, as shown in Fig. 6, is used to predict the actuator efficiency under the influence of road disturbances with the parameters given in Table II. The degrees of freedom include the vertical movement of the sprung $\left(z_{s}\right)$ and unsprung mass $\left(z_{u}\right)$. The road disturbance is typically modeled as a white noise disturbance with a first-order filter [13], i.e.,

$$
H_{z r}=\frac{1}{\frac{s}{a V_{x}}+1}
$$

Together with a gain for the white noise $K_{\text {road }}$, which is fitted on a sample time $t_{s}$ of $1 \mathrm{~ms}$, various road types can be described, 


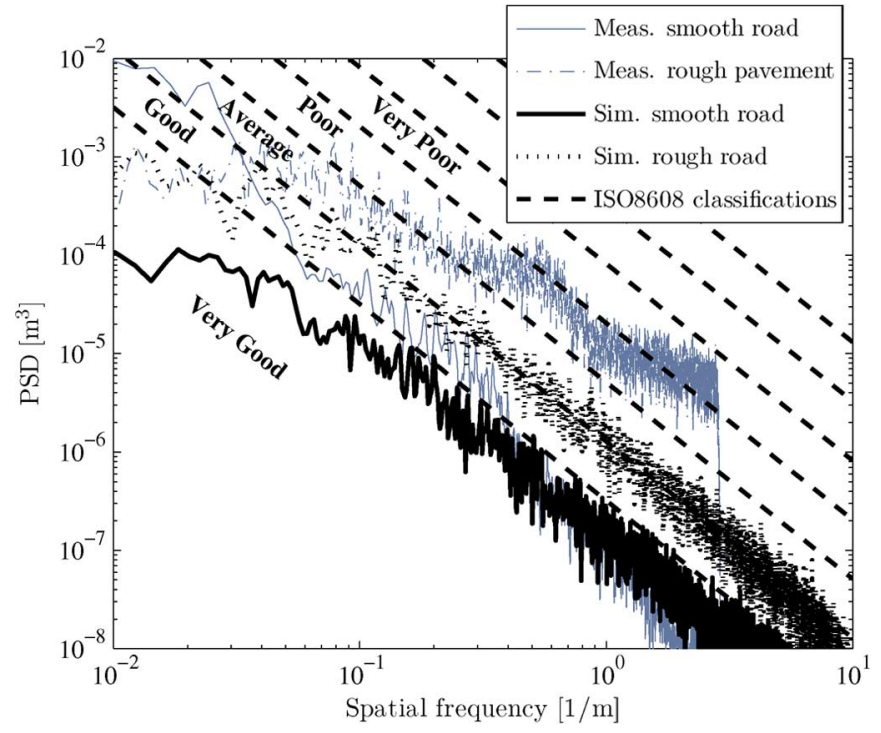

Fig. 7. PSD spectra of the simulated and measured road profiles.

TABLE III

PARAMETERS OF THE ROAD PROFILES

\begin{tabular}{|c||c||c||c|}
\hline Road type & $a(\mathrm{rad} / \mathrm{m})$ & $K_{\text {road }}(\mathrm{m})$ & $V_{x}(\mathrm{~m} / \mathrm{s})$ \\
\hline Smooth asphalt & 0.2 & 0.05 & 30 \\
\hline Rough pavement & 0.8 & 0.125 & 7.5 \\
\hline
\end{tabular}

depending on the forward velocity $V_{x}$ and the shaping parameter $a$. The power spectral density (PSD) of the measured road profile $z_{r}$ as a function of the spatial frequency is calculated through the method described by Welch [14]. The PSD of the white noise together with the proposed road filter $H_{z r}$ is defined by

$$
P S D_{z_{r}}=K_{\text {road }}^{2} V_{x} t_{s}\left|H_{z r}\right|^{2} .
$$

Fig. 7 shows the PSD of two typical road profiles together with the measurements for the smooth asphalt and very rough pavement; furthermore, the International Standards Organization (ISO) 8608 lines [15] are shown. The -2 slope is clearly shown in this figure. The typical road parameters used in this paper are summarized in Table III. The quarter-car model including road disturbances is generally modeled in state space as

$$
\begin{aligned}
& \dot{x}=A x+B u+G w \\
& y=C x+D u
\end{aligned}
$$

where $w$ is the white noise input, $u$ is the input given by the actuator force $F_{a c t}$, and $x$ is the state vector given by

$$
x=\left[\begin{array}{lllll}
z_{s} & \dot{z}_{s} & z_{u} & \dot{z}_{u} & z_{r}
\end{array}\right]^{T} .
$$

TABLE IV

WEIGHTING FACTORS

\begin{tabular}{|c||c||c||c|}
\hline Objective & $q_{1}$ & $q_{2}$ & $q_{3}$ \\
\hline Comfort & $6.324 \times 10^{-5}$ & $2.248 \times 10^{3}$ & $1.691 \times 10^{6}$ \\
\hline Tire load & $5.80 \times 10^{-4}$ & 2.361 & $5.657 \times 10^{4}$ \\
\hline
\end{tabular}

TABLE V

PERFormance DATA OF THE PASSIVE BMW 530I SUSPENSION

\begin{tabular}{|c||c||c||c|}
\hline Road & $a_{c}\left(\mathrm{~m} / \mathrm{s}^{2}\right)$ & $F_{t}(\mathrm{~N})$ & $\max (z)(\mathrm{mm})$ \\
\hline Smooth asphalt & 0.542 & 381 & 12.388 \\
\hline Rough pavement & 1.10 & 1017 & 31.723 \\
\hline
\end{tabular}

Matrices $A, B$, and $G$ now become

$$
\begin{aligned}
A & =\left[\begin{array}{ccccc}
0 & 1 & 0 & 0 & 0 \\
-\frac{k_{s}}{m_{s}} & -\frac{d_{s}}{m_{s}} & \frac{k_{s}}{m_{s}} & \frac{d_{s}}{m_{s}} & 0 \\
0 & 0 & 0 & 1 & 0 \\
\frac{k_{s}}{m_{u}} & \frac{d_{s}}{m_{u}} & -\frac{\left(k_{s}+k_{t}\right)}{m_{u}} & -\frac{d_{s}}{m_{u}} & \frac{k_{t}}{m_{u}} \\
0 & 0 & 0 & 0 & -a v
\end{array}\right] \\
B & =\left[\begin{array}{lllll}
0 & \frac{1}{m_{s}} & 0 & -\frac{1}{m_{s}} & 0
\end{array}\right]^{T} \\
G & =\left[\begin{array}{lllll}
0 & 0 & 0 & 0 & 1
\end{array}\right]^{T} .
\end{aligned}
$$

With matrices $C$ and $D$, the output variables are determined. Of interest here are the vehicle comfort and road holding with constraint to suspension travel. This condition results in the following $C$ and $D$ matrices:

$$
\begin{aligned}
C & =\left[\begin{array}{ccccc}
0 & 0 & k_{t} & 0 & -k_{t} \\
-\frac{k_{s}}{m_{s}} & -\frac{d_{s}}{m_{s}} & \frac{k_{s}}{m_{s}} & \frac{d_{s}}{m_{s}} & 0 \\
1 & 0 & -1 & 0 & 0
\end{array}\right] \\
D & =\left[\begin{array}{c}
0 \\
\frac{1}{m_{s}} \\
0
\end{array}\right] .
\end{aligned}
$$

Control of the active suspension is performed using an LQR controller, where it is assumed that the full state is measurable [16] and the system is linear with all the parameters known [17] or is successfully estimated as shown, for example, in [18]. A quadratic weighting criterion [19] is used such that, by choosing the weighting factors (see Table IV), one or two of the criteria can be emphasized. Furthermore, the actuator forces and speeds have to be within the specifications, and the maximum suspension travel should be smaller than or equal to the suspension travel of the passive BMW strut for fair comparison. The performance of the vehicle with passive suspension is summarized in Table V. The criterion reads

$$
\begin{aligned}
J & =\lim _{t_{e} \rightarrow \infty} \int_{0}^{t_{e}}(C x+D u)^{T} Q(C x+D u) d t \\
& =\int_{0}^{t_{e}}\left[\begin{array}{ll}
x^{T} & u^{T}
\end{array}\right]\left[\begin{array}{ll}
C^{T} Q C & C^{T} Q D \\
D^{T} Q C & D^{T} Q D
\end{array}\right]\left[\begin{array}{ll}
x & u
\end{array}\right] d t
\end{aligned}
$$




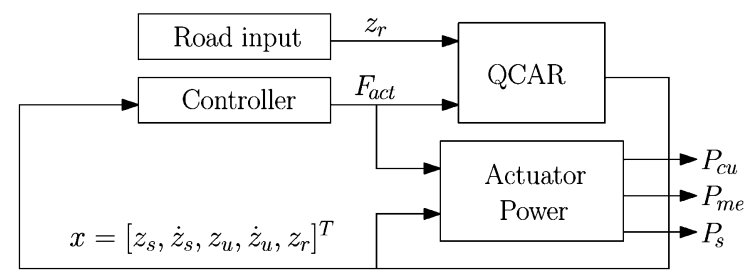

Fig. 8. Block scheme of the total model.

where $Q$ is chosen to be a diagonal matrix that contains the weighting factors. Variation calculus and differentiation leads to the state feedback [20], i.e.,

$$
u(t)=-K x
$$

where $K$ is given as

$$
K=R^{-1}\left(N_{c}^{T}+B^{T} P\right) .
$$

and $P$ is the solution of the Riccati equation. The weighting factors contained in the matrix $Q$, which are obtained through a constrained nonlinear optimization algorithm, are summarized in Table IV. In Fig. 8, the block scheme of the total modeling strategy performed in Matlab Simulink is given. The road input $z_{r}$ and the calculated actuator force $F_{a c t}$ are the inputs for the vehicle dynamics of the quarter-car model. The resulting state vector $x$ is then measured and used as an input for the controller $K$. The desired actuator force and the dynamics given by the state vector determine the consumed or obtained power of the active suspension system through (4)-6). When the full-car dynamics are considered, the quarter-car model can be extended to the full-car model as given in [21]. This model allows for the inclusion of roll, pitch, and yaw control and facilitates the calculation of the resulting power consumption of these control strategies. However, this case is outside the scope of this paper.

\section{Simulations}

In total, four different situations are simulated, and for every situation and for passive damping values $d_{p}$ ranging from 0 $\mathrm{Ns} / \mathrm{m}$ to $2000 \mathrm{Ns} / \mathrm{m}$, the average mechanical power, supply power, and copper losses are calculated. The results for the comfort objective are shown in Fig. 9(a) and (c) for smooth and rough roads, respectively. It can be observed that the actuator works in the generation mode $\left(P_{m e}<0\right)$ when $d_{p}$ is smaller than $287 \mathrm{Ns} / \mathrm{m}$ and in the motor mode beyond. For a comfort setting, the total damping is required to be relatively low, and therefore, the actuator forces are relatively low (see Fig. 10) for low passive damping, resulting in low copper losses. Hence, the overall efficiency is optimal for low passive damping, as shown in Fig. 11. When the passive damping increases, the actuator needs to lower this passive damping (and hence should work in the motor mode) and changes the system from delivering energy to consuming energy. The power levels for the tire load objective are shown in Fig. 9(b) and (d) for smooth and rough roads, respectively. The actuator works in the generator mode up to $1845 \mathrm{Ns} / \mathrm{m}$, because a tire load setting requires a very stiff suspension system (high damping). Furthermore, the copper losses are more significant, because higher actuator forces are necessary (see Fig. 10 ). This case results in a zero overall efficiency up to $d_{p}=1845 \mathrm{Ns} / \mathrm{m}$, and beyond this point, the actuator works in the motor mode. For the tire load setting, the actuator works as a generator; however, all the energy is dissipated, because extreme force levels are required to obtain the required handling. The improvement in percentage for the comfort and tire load settings compared to the passive BMW suspension are independent of $d_{p}$ and are shown in Table VI, where a positive number corresponds to an improvement. To calculate the comfort, the sprung acceleration is weighted according to the ISO 2631 criterion [22]. Because each controller in its turn focuses on either comfort or dynamic tire load, only an improvement on one of the criteria is expected. In general, the control design is a tradeoff between both criteria, or adaptive control should be applied to combine both benefits. Furthermore, the choice of $d_{p}$ is closely related to the fail-safe operation, where passive damping is necessary, which will reduce the amount of regenerated power, as can be observed in Fig. 9(a) and (c). A time plot of the required actuator forces for a smooth road is presented in Figs. 12(a) and 13(a) for $d_{p}=0 \mathrm{Ns} / \mathrm{m}$ and $d_{p}=1600 \mathrm{Ns} / \mathrm{m}$, respectively, where it can be observed that the required performance of the actuator is higher for the tire load objective in terms of peak and rms force and bandwidth. The sprung acceleration for both damping values are shown in Figs. 12(b) and 13(b), where, for the comfort objective, the $71.47 \%$ improvement in acceleration level is clearly visible. In Figs. 12(c) and 13(c), the tire load for both damping values is shown, where, for the tire load objective, an improvement of $52.53 \%$ is observed. Comparing Figs. 12 and 13 , it can be observed that, for both values of damping, the same performance in comfort or handling is achieved. Finally, the necessary supply power for both cases is shown in Figs. 14 and 15 for $d_{p}=0 \mathrm{Ns} / \mathrm{m}$ and $d_{p}=1600 \mathrm{Ns} / \mathrm{m}$, respectively. For the case $d_{p}=0 \mathrm{Ns} / \mathrm{m}$ (see Fig. 14), it is shown that, for the comfort objective, on the average, the supply power is negative, implying that energy is regenerated from the road vibrations. For both cases, the supply power for the tire load objective has much more high-frequency content. This case is because, for the comfort objective, the road input is filtered by the double mass-spring-damper system, whereas to reduce the tire load, the high frequency road vibrations directly act on the tire.

\section{Quarter-Car Test SeTuP}

To verify the results obtained with the simulations, measurements were performed on a quarter-car setup, as shown in Fig. 16, where the schematic representation is given in Fig. 17. The road disturbances are performed by an industrial tubular actuator [see Fig. 17(a)] in parallel with a spring to support the weight of the total moving mass of the setup. A proportional-integral-differential (PID) controller with notches is used to control the industrial tubular actuator, which follows the reference signal $z_{r}$, as formulated in Section III. The tire stiffness $k_{w}$ and unsprung mass $M_{u}$, as modeled in Section III, are represented by a coil spring and a mass [see Fig. 17(b) and (c), respectively] 
(a)

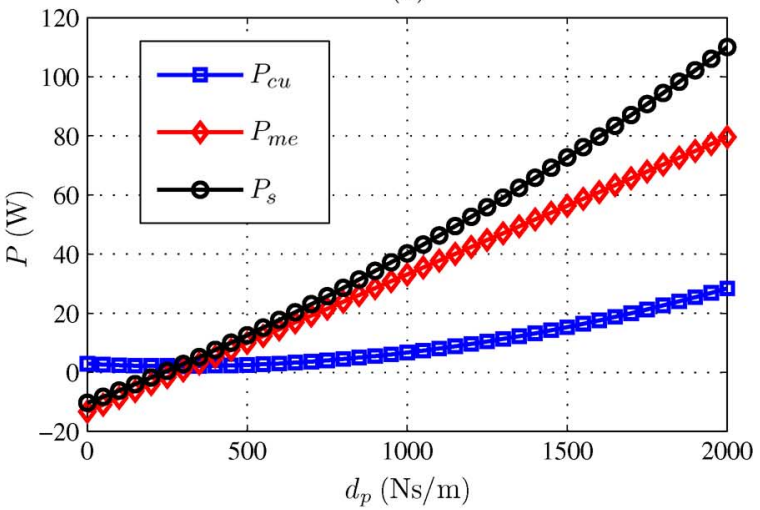

(c)

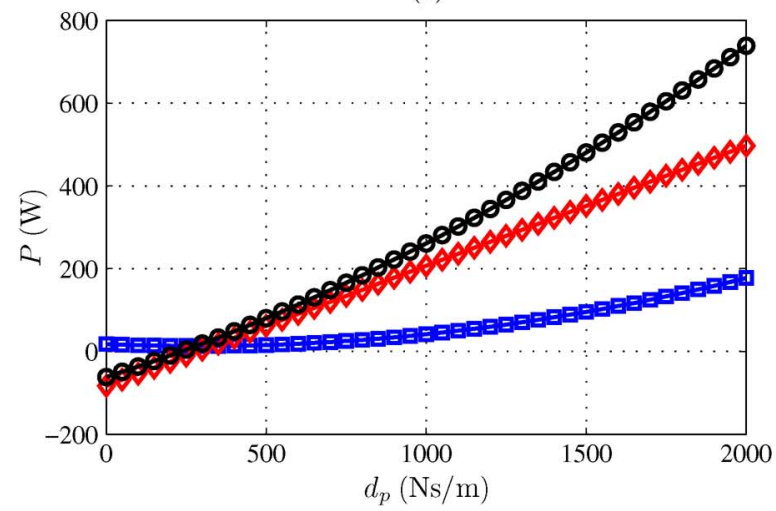

(b)

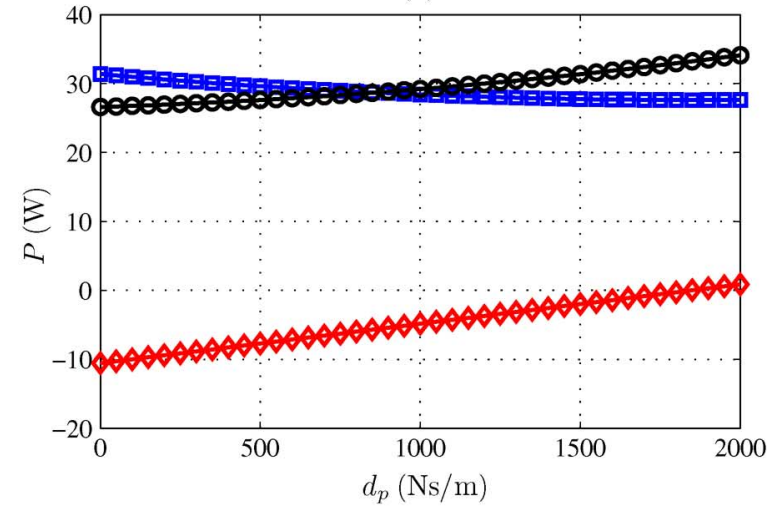

(d)

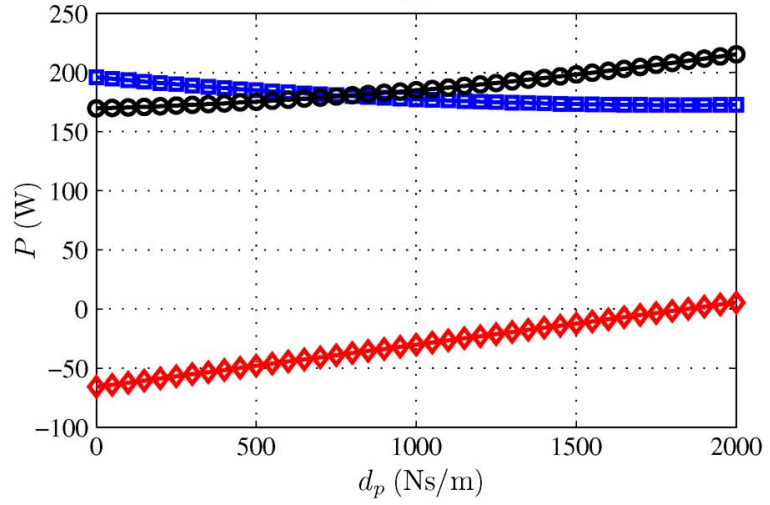

Fig. 9. Average power as a function of the passive damping for the various objective/road situations. (a) Comfort/Smooth road. (b) Tire load/Smooth road. (c) Comfort/Rough road. (d) Tire load/Rough road.

with equivalent values, as shown in Table II. The unsprung mass is connected to the sprung mass [see Fig. 17(e)] through the suspension strut [see Fig. 17(d) ]. The setup has been designed such that the suspension strut can be replaced for either the passive or the active strut. Both masses are guided by linear bearings, allowing only a movement in the $z$-direction. Because the acceleration of the sprung mass is a good indication of comfort, it is directly measured using a Kistler 8330A3 accelerometer. Furthermore, the acceleration of the unsprung mass is measured using a Kistler 8305B50 accelerometer. Because the suspension travel $z$ is necessary to commutate the actuator and is a constraint of the suspension system, it is measured using a MicroEpsilon ILD1402-200SC laser sensor. A similar sensor is used to measure the tire compression $z_{t}$. Finally, the road position $z_{r}$ is measured using an incremental encoder that was attached to the industrial tubular actuator. Using these measurements, the full state is reconstructed as

$$
\begin{aligned}
z_{u} & =z_{t}+z_{r} \\
z_{s} & =z+z_{u} \\
\dot{z}_{s} & =\frac{d z_{s}}{d t} \\
\dot{z}_{u} & =\frac{d z_{u}}{d t}
\end{aligned}
$$

Furthermore, the three-phase currents and voltages are measured to determine the supply power of the active suspension

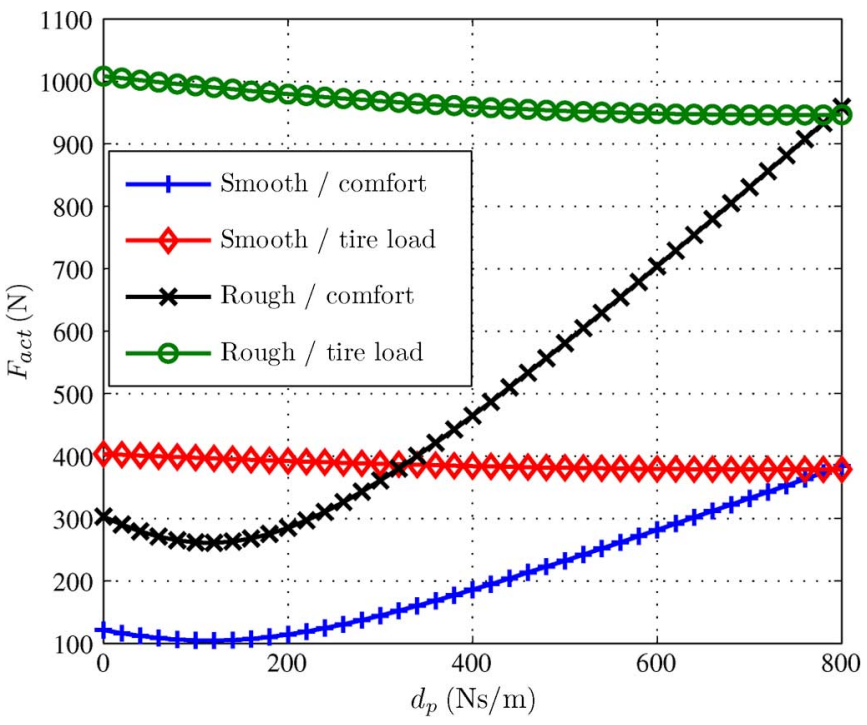

Fig. 10. Actuator force as a function of the passive damping for every situation.

system. The aforementioned analysis was performed for a varying value of passive damping $d_{p}$. The prototype electromagnetic active suspension, however, is designed with fail-safe passive damping, where the value of $d_{p}$ is around $1600 \mathrm{Ns} / \mathrm{m}$. Hence, only the performance data for this value of $d_{p}$ will experimentally be verified. Fig. 18 shows the PSDs of the simulated and measured quarter-car model. As shown in this figure, 


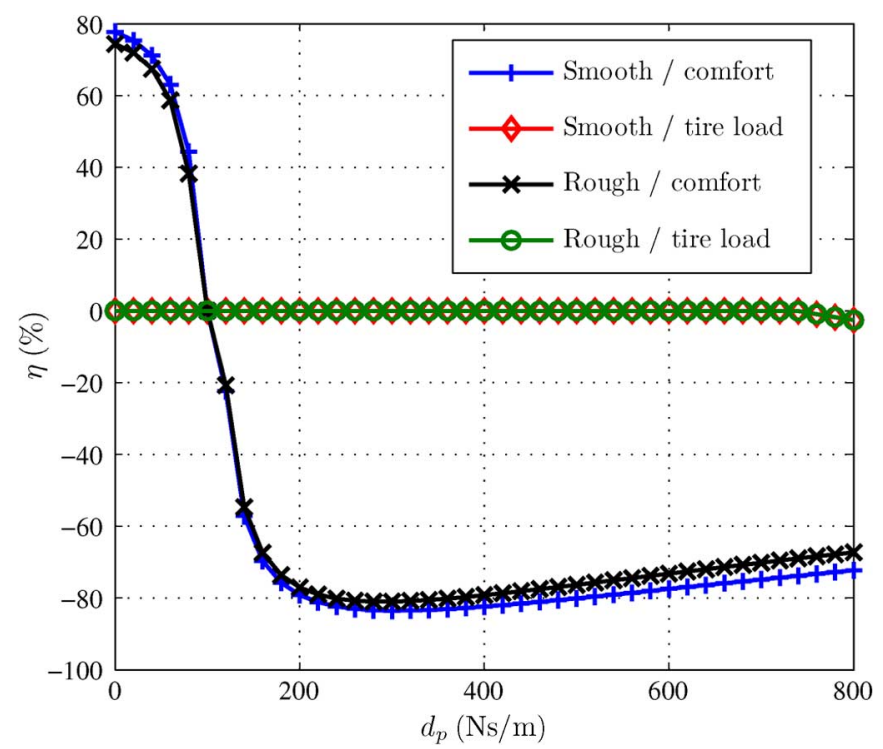

Fig. 11. Efficiency as a function of the passive damping for every situation.

TABLE VI

IMPROVEMENT IN \% PERFORMANCE COMPARED TO THE PASSIVE BMW SUSPENSION

\begin{tabular}{|c||c||c||c||}
\hline Road / Obj. & RMS ISO $a_{c}$ & RMS $F_{t}$ & Maximum $z$ \\
\hline Smooth / Comfort & 71.47 & -144.9 & 11.51 \\
\hline Rough / Comfort & 64.86 & -129.4 & 29.34 \\
\hline Smooth / Tire load & -24.50 & 52.53 & 13.61 \\
\hline Rough / Tire load & -53.39 & 55.54 & 31.01 \\
\hline
\end{tabular}

(a)

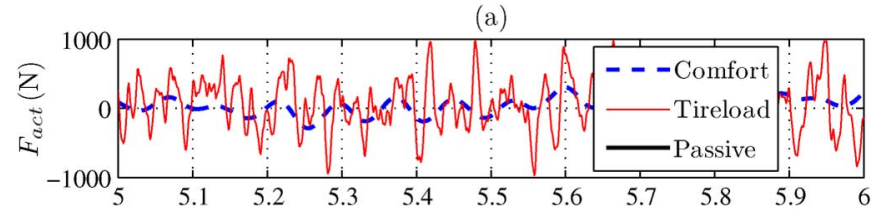

(b)

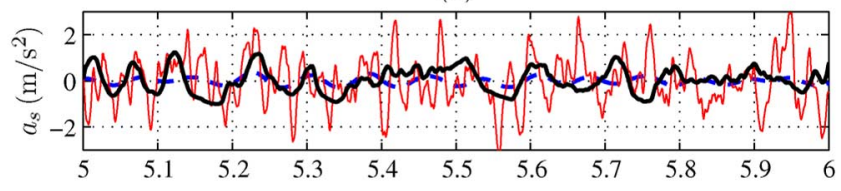

(c)

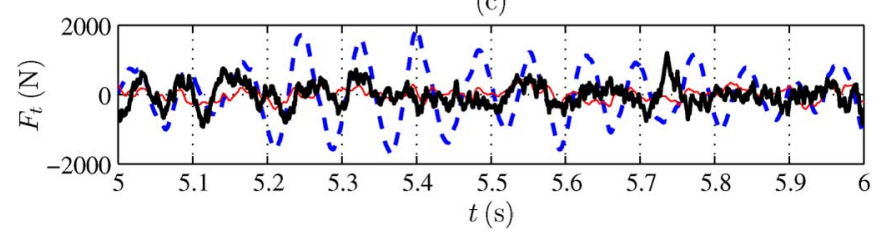

Fig. 12. (a) Actuator force, (b) sprung acceleration, and (c) tire load for $d_{p}=$ $0 \mathrm{Ns} / \mathrm{m}$, emphasizing comfort and dynamic tire load for a smooth road.

up to $30 \mathrm{~Hz}$, the simulated and measured roads are similar, and above this frequency, the industrial actuator cannot follow the road signal. This case is, however, not a problem, because frequencies up to $30 \mathrm{~Hz}$ are of most interest when considering the ISO 2631-1 weighting criterion. Furthermore, it is shown that the PSDs of the sprung and unsprung acceleration and the suspension travel closely match. At $65 \mathrm{~Hz}$, a resonance peak can be observed in the measurements, and this resonance is

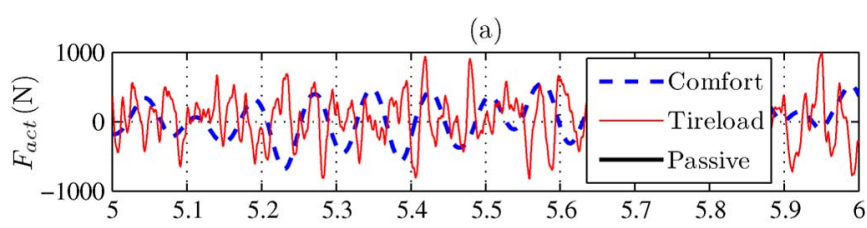

(b)

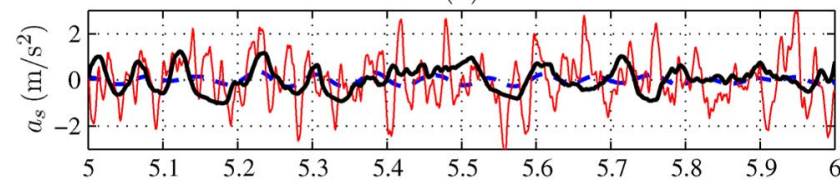

(c)

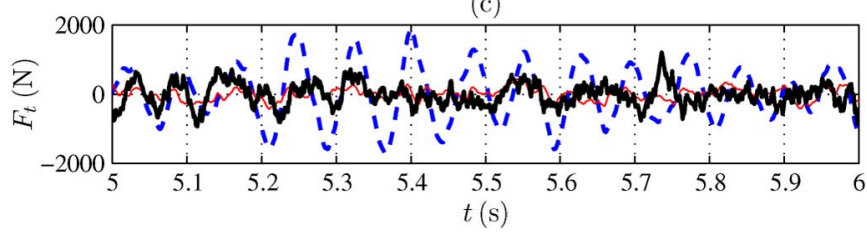

Fig. 13. (a) Actuator force, (b) sprung acceleration, and (c) tire load for $d_{p}=$ $1600 \mathrm{Ns} / \mathrm{m}$, emphasizing comfort and dynamic tire load for a smooth road.

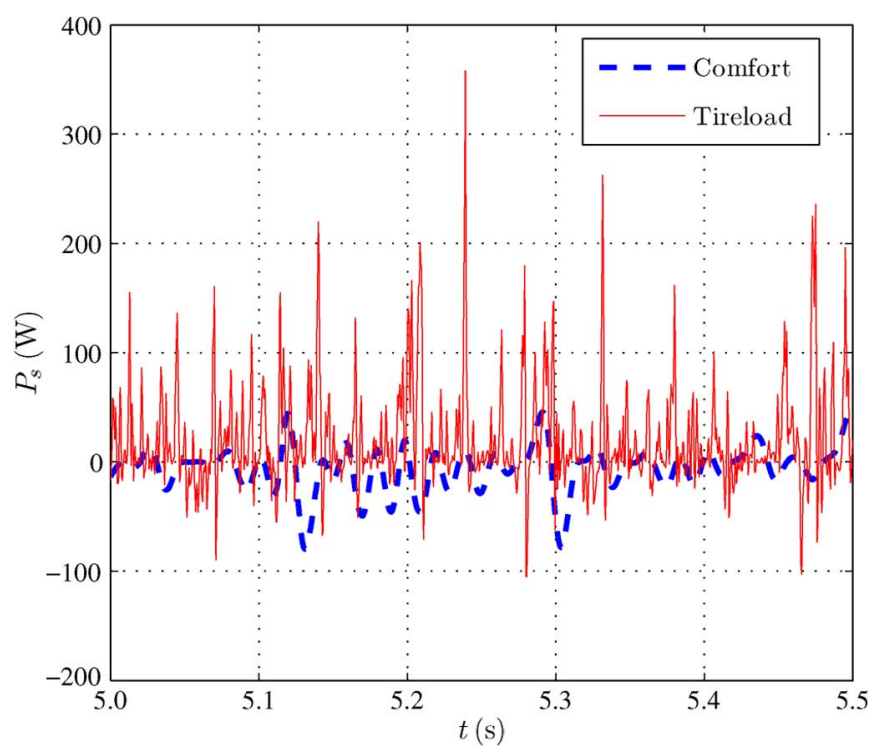

Fig. 14. Supply power for $d_{p}=0 \mathrm{Ns} / \mathrm{m}$ for the comfort and tire load objectives.

caused by the windings of the support spring in parallel with the industrial tubular actuator.

This setup could be extended to a half- or full-car setup; however, considering the costs, it is more beneficial to use a real car on top of four electromagnetic shakers. This way, the real geometry of the total suspension system is included, as well as the rubbers and bushings of the suspension. Furthermore, the correct bending and torsional modes of the car chassis are included.

The situation with rough road in combination with the tire load objective could not be performed, because the industrial actuator cannot deliver the desired forces due to the high dynamic load of the active suspension system, as Fig. 10 predicts. Furthermore, the situation with rough road in combination with the comfort objective can be performed for only $50 \%$ of the rough road gain $K_{\text {road }}$. Fig. 19 compares the ISO weighted sprung acceleration achieved with simulations and measurements. It can 


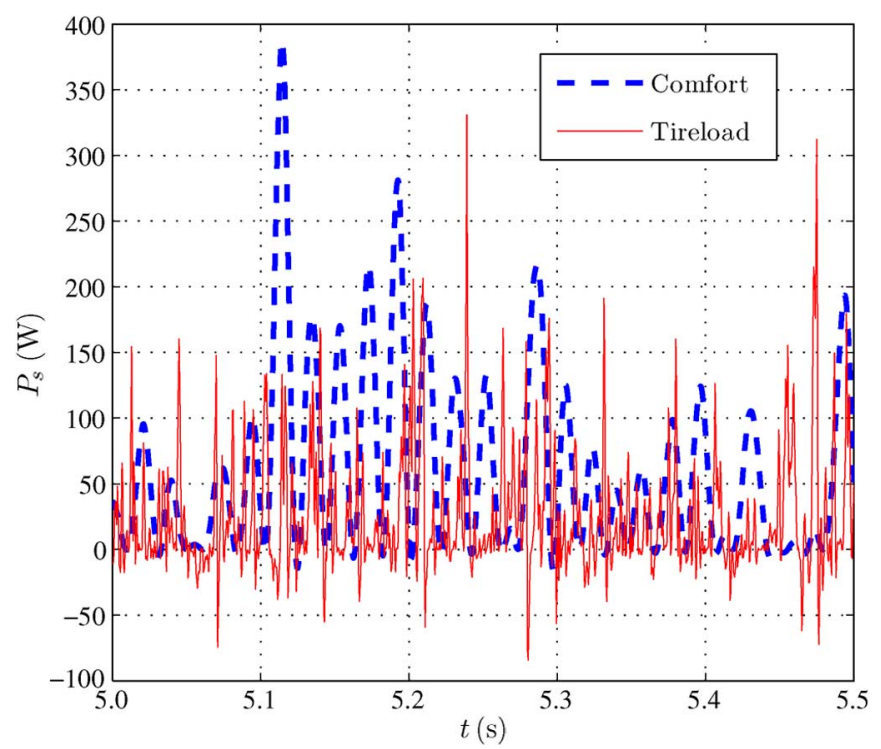

Fig. 15. Supply power for $d_{p}=1600 \mathrm{Ns} / \mathrm{m}$ for the comfort and tire load objectives.

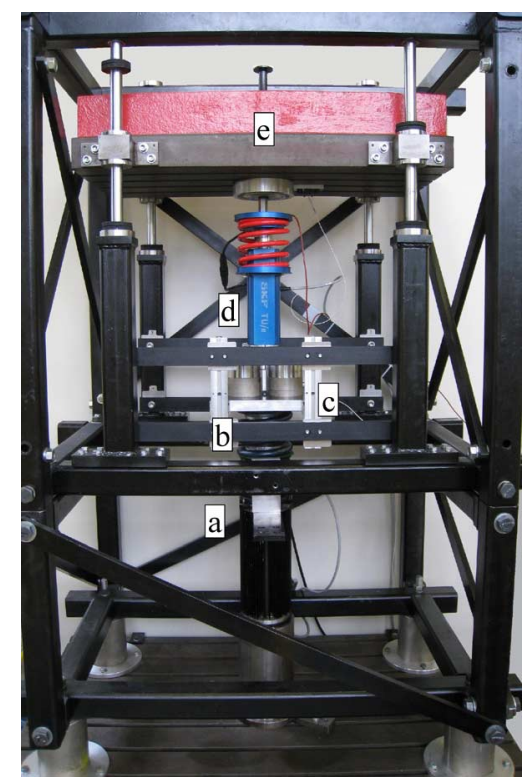

Fig. 16. Quarter-car test setup.

be observed that, although the measured values differ from the simulated values, a clear correlation is visible. When emphasizing comfort, acceleration values are clearly lower than the passive BMW suspension (36\% for the smooth road and $43 \%$ for $50 \%$ of the rough road). The difference between the simulations and the measurements can be accounted for by unmodeled cogging forces of the active suspension and the stick-slip friction of the actuator, which become dominant at lower acceleration levels. Furthermore, vibrations are still conducted through the bearings of the test setup. These effects are less visible for the handling controller due to the relatively higher acceleration levels. The dynamic tire load comparisons are shown in Fig. 20, where a similar correlation can be observed, which can be attributed to the same reasons as shown in Fig. 19. An improvement of $54 \%$ in handling for the smooth road is obtained com-

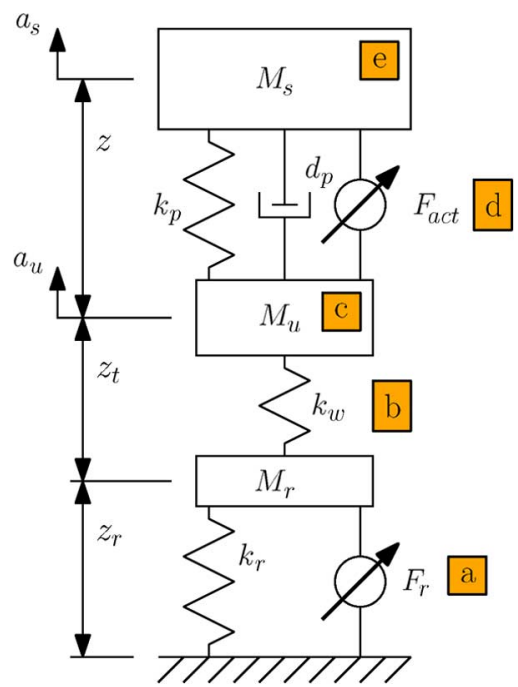

Fig. 17. Schematic of the quarter-car test setup.
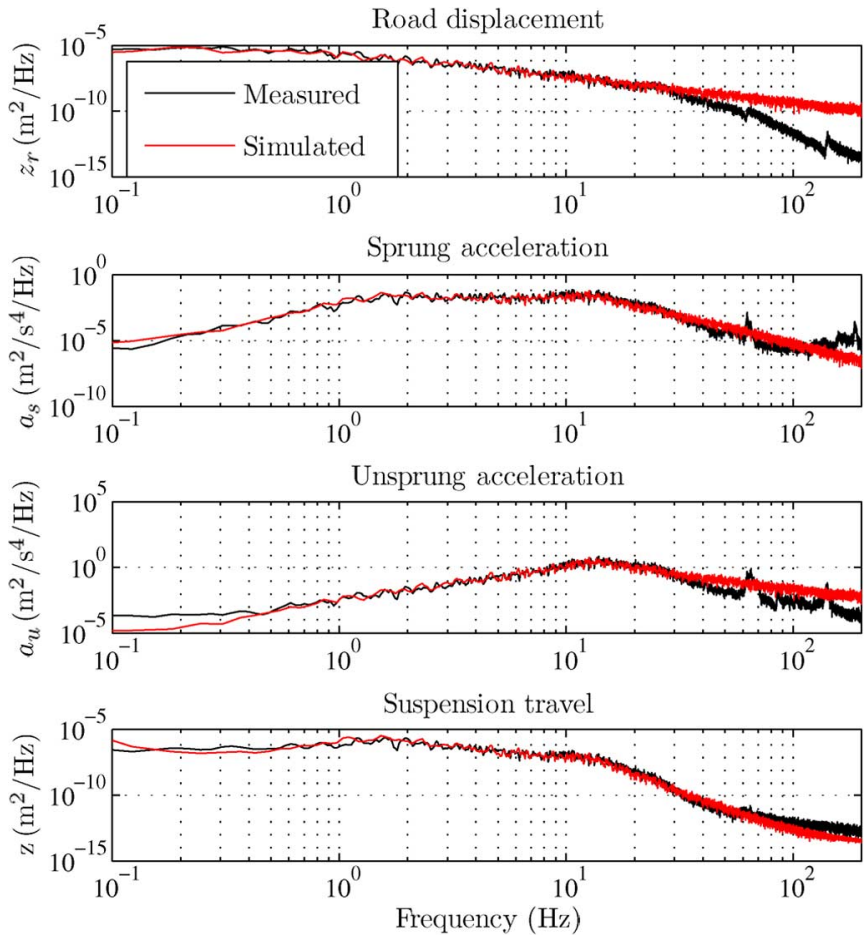

Fig. 18. PSD of road input, sprung acceleration, unsprung acceleration, and suspension travel for a smooth road of the quarter-car test setup.

pared with the passive BMW suspension. The actuator forces are compared in Fig. 21, where, for the comfort objective, a good correlation is obtained. However, a clear difference is apparent for the handling objective for a smooth road, which is caused by the unmodeled resonance peak at $65 \mathrm{~Hz}$ of the support spring in parallel with the road actuator. To minimize the tire load variation, this resonance has to be minimized, which results in a higher actuator force at that particular frequency than in the model. Fig. 22 relates the actuator supply power of the simulations with the measurements. The average power consumption for the comfort objective is lower for the measurements. Because the body acceleration levels are higher, the corresponding 


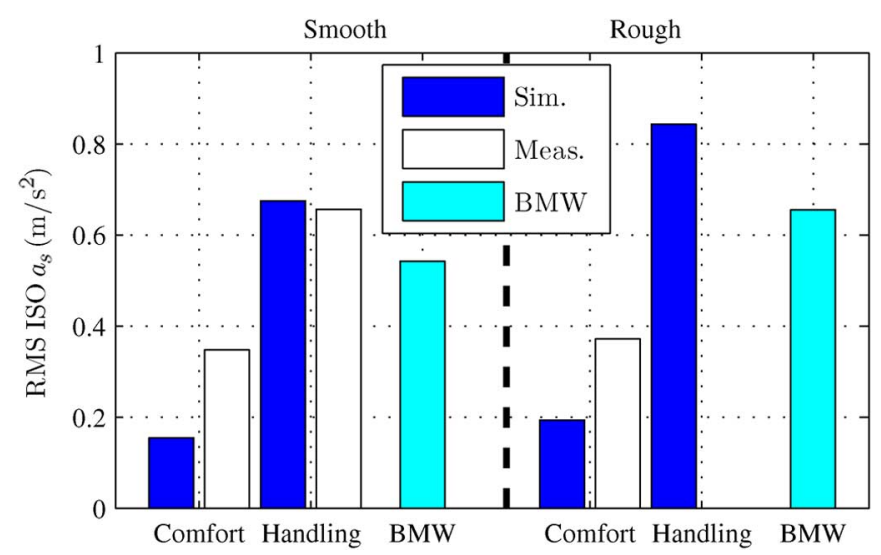

Fig. 19. Simulated and measured rms ISO weighted sprung acceleration.

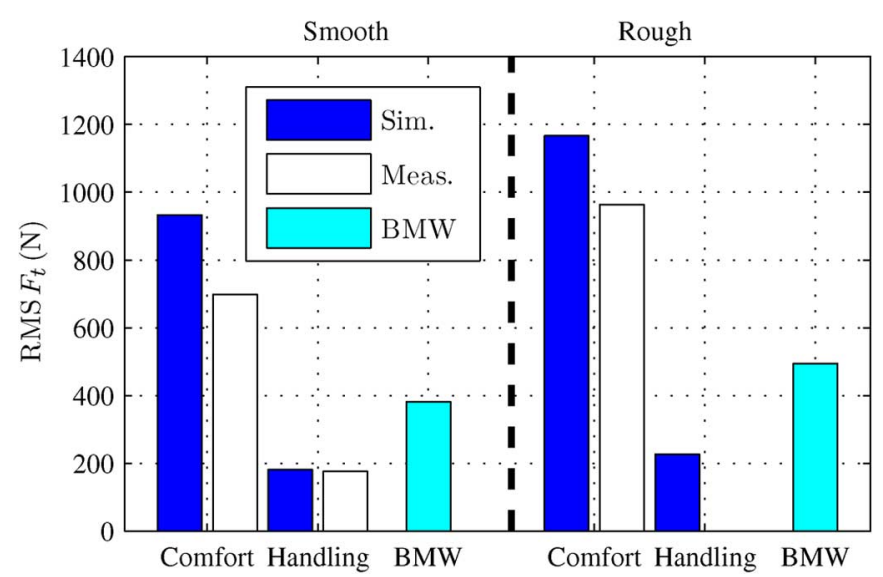

Fig. 20. Simulated and measured rms dynamic tire load.

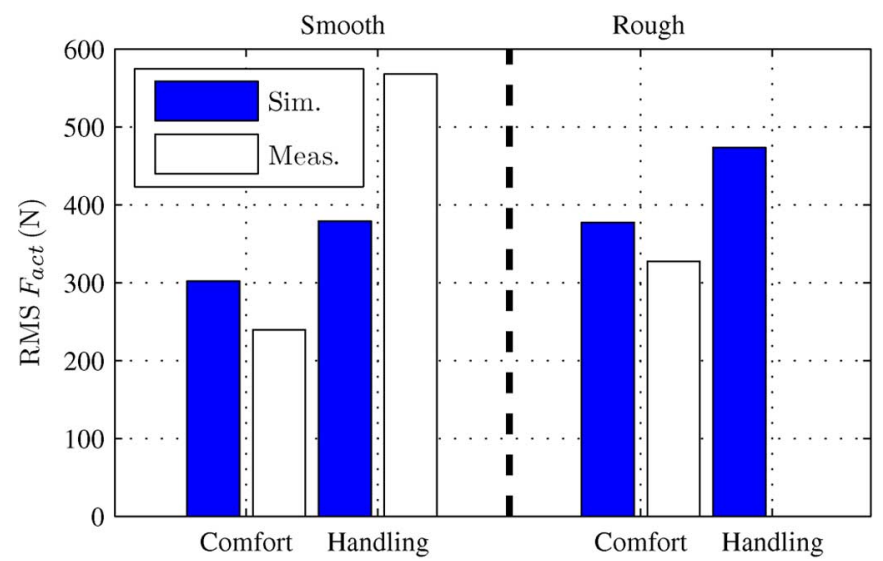

Fig. 21. Simulated and measured rms actuator forces.

suspension travel and speed will be lower; hence, the mechanical output power is lower. Furthermore, the actuator force for this objective is lower than the measurements (see Fig. 21), resulting in lower copper losses. A snapshot of the supply power for the comfort and tire load objective for the smooth road is given in Fig. 23, where the supply power for the tire load objective has a higher frequency content, as observed during simulation.

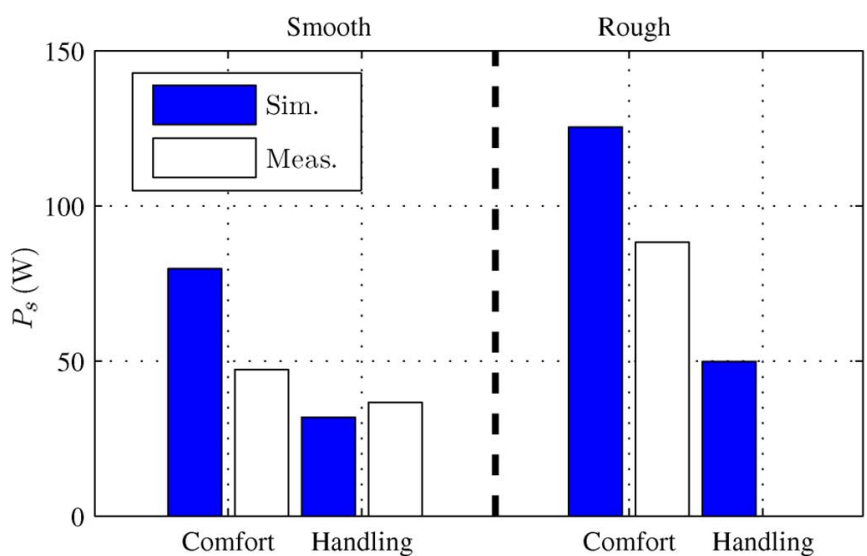

Fig. 22. Simulated and measured supply power.

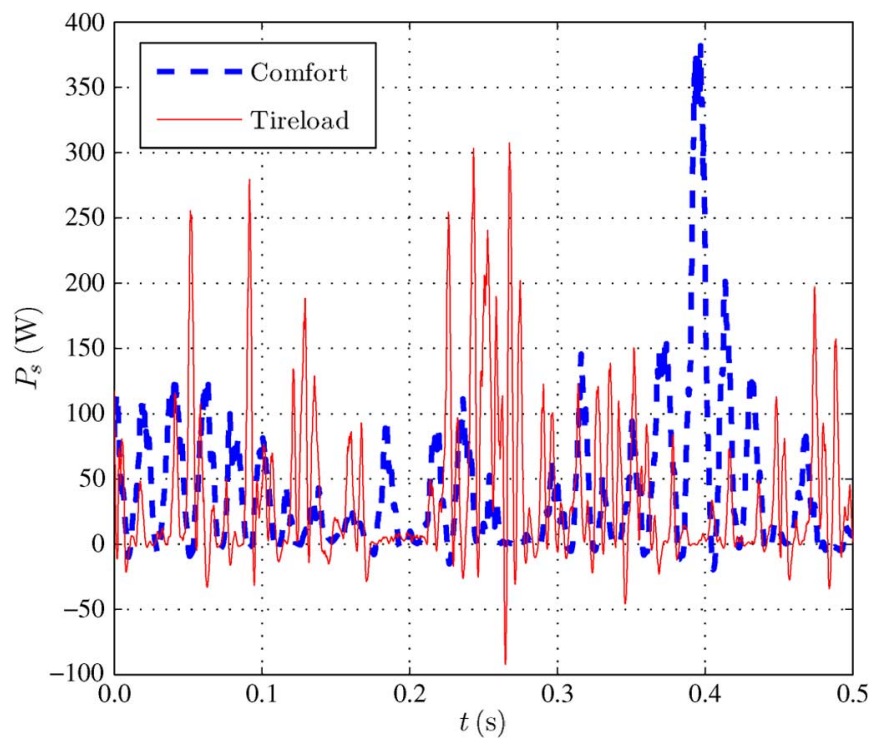

Fig. 23. Time plot of the supply power for a smooth road and both objectives.

\section{CONCLUSION}

A direct-drive active suspension that comprises a TPMA in parallel with a coil spring has been considered for the objectives of improvement in comfort or reduction of the dynamic tire load. The suspension system can generate power as a result of the various road vibrations. Two different road profiles are defined based on measurements, and two LQR controllers are derived for both objectives. The efficiency of this electromechanical system was defined and simulated for the various situations. For safety reasons, a passive damping should be present; however, this condition strongly influences the efficiency of the suspension system. Lower passive damping results in higher efficiency for the comfort objective; however, for the tire load objective, no energy can be recuperated due to the required force levels and corresponding copper losses. Measurements were performed on a quarter-car test setup with a prototype electromagnetic suspension system with a relatively high damping (considering the fail-safe system) on a smooth road. For the comfort objective, a reduction of $36 \%$ in ISO weighted sprung acceleration is obtained at the expense of $47 \mathrm{~W}$ per wheel, and for the tire load objective, a reduction of $54 \%$ in the dynamic tire load is achieved 
at the expense of $37 \mathrm{~W}$ per wheel. These results indicate that this electromagnetic suspension system can significantly improve both comfort and handling with minimal power requirements of between 150- and 300-W overall power consumption for the total vehicle, depending on road conditions and objectives. Considering a different passive damping, the power consumption can further be reduced.

\section{REFERENCES}

[1] K. Cakir and A. Sabanovic, "In-wheel motor design for electric vehicles," in Proc. 9th IEEE Int. Workshop Adv. Motion Control, 2006, pp. 613-618.

[2] B. L. J. Gysen, J. J. H. Paulides, J. L. G. Janssen, and E. A. Lomonova, "Active electromagnetic suspension system for improved vehicle dynamics," IEEE Trans. Veh. Technol., vol. 59, no. 3, pp. 1156-1163, Mar. 2010.

[3] B. Jacobsen, "Potential of electric wheel motors as new chassis actuators for vehicle maneuvering ," Proc. Inst. Mech. Eng.-Part D: J. Automobile Eng., vol. 216, no. 8, pp. 631-640, Mar. 2002.

[4] I. Martins, J. Esteves, G. D. Marques, and F. P. da Silva, "Permanent-magnet linear actuators applicability in automobile active suspensions," IEEE Trans. Veh. Technol., vol. 55, no. 1, pp. 86-94, Jan. 2006.

[5] B. L. J. Gysen, T. P. J. van der Sande, J. J. H. Paulides, and E. A. Lomonova, "Efficiency of a regenerative direct-drive electromagnetic active suspension," in Proc. IEEE VPPC, Sep. 2010, pp. 1-6.

[6] B. L. J. Gysen, J. J. H. Paulides, L. Encica, and E. A. Lomonova, "Slotted tubular permanent-magnet actuator for active suspension systems," in Proc. 7th Int. Symp. LDIA, Sep. 2009, pp. 292-295.

[7] P. Hsu, "Power recovery property of electrical active suspension systems," in Proc. 31st IECEC, Aug. 11-16, 1996, vol. 3, pp. 1899-1904.

[8] M. Montazeri-Gh and M. Soleymani, "Investigation of the energy regeneration of active suspension system in hybrid electric vehicles ," IEEE Trans. Ind. Electron., vol. 57, no. 3, pp. 918-925, Mar. 2010.

[9] J. Wang, W. Wang, and K. Atallah, "A linear permanent-magnet motor for active vehicle suspension," IEEE Trans. Veh. Technol., vol. 60, no. 1, pp. 55-63, Jan. 2011.

[10] B. L. J. Gysen, J. L. G. Janssen, J. J. H. Paulides, and E. A. Lomonova, "Design aspects of an active electromagnetic suspension system for automotive applications ," IEEE Trans. Ind. Appl., vol. 45, no. 5, pp. 1589-1597, Sep./Oct. 2009.

[11] J. Wang, W. Wang, K. Atallah, and D. Howe, "Comparative studies of linear permanent-magnet motor topologies for active vehicle suspension," in Proc. IEEE VPPC, Sep. 2008, pp. 1-6.

[12] S. Lee and W. J. Kim, "Active suspension control with direct-drive tubular linear brushless permanent-magnet motor ," IEEE Trans. Control Syst. Technol., vol. 18, no. 4, pp. 859-870, Jul. 2010.

[13] P. Michelberger, L. Palkovics, and J. Bokor, "Robust design of active suspension system," Int. J. Veh. Des., vol. 14, no. 2/3, pp. 145-165, 1993.

[14] P. Welch, "The use of fast Fourier transform for the estimation of power spectra: A method based on time averaging over short, modified periodograms," IEEE Trans. Audio Electroacoust., vol. AU-15, no. 2, pp. 70-73, Jun. 1967.

[15] Mechanical Vibration-Road Surface Profiles: Reporting of Measured Data, ISO 8608:1995, 1995, ISO, International Organization for Standardization, Geneva, Switzerland, Tech. Rep..

[16] M. M. Elmadany and Z. S. Abduljabbar, "Linear quadratic Gaussian control of a quarter-car suspension," Veh. Syst. Dyn., vol. 32, no. 6, pp. 479-497, Dec. 1999.

[17] D. Mantaras and P. Luque, "Ride comfort performance of different active suspension systems," Int. J. Veh. Des., vol. 40, no. 1-3, pp. 106-125, 2006.

[18] L.-Y. Hsu and T.-L. Chen, "Vehicle full-state estimation and prediction system using state observers," IEEE Trans. Veh. Technol., vol. 58, no. 6, pp. 2651-2662, Jul. 2009.

[19] D. Hrovat, "Survey of advanced suspension developments and related optimal control applications ," Automatica, vol. 33, no. 10, pp. 1781-1817, Oct. 1997.
[20] H. Kwakernaak and R. Sivan, Linear Optimal Control Systems. Hoboken, NJ: Wiley, 1972.

[21] A. Kruczek and A. Stribrsky, "A full-car model for active suspension-Some practical aspects," in Proc. IEEE Int. Conf. Mechatron. 2004, pp. 41-45.

[22] Mechanical Vibration and Shock-Evaluation of Human Exposure to Whole-Body Vibration, ISO 2631-1:1997, 1997, ISO, International Organization for Standardization, Geneva, Switzerland, Tech. Rep..

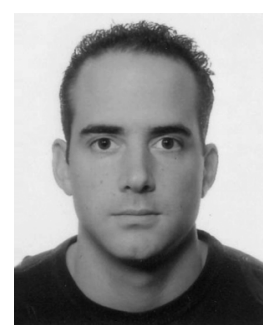

Bart L. J. Gysen (S'07-M'10) was born in Bilzen, Belgium, in 1984. He received the B.Sc. and M.Sc. degrees in electrical engineering from the Eindhoven University of Technology, Eindhoven, The Netherlands. He is currently working toward the Ph.D. degree with the Department of Electrical Engineering, Eindhoven University of Technology, with the Electromechanics and Power Electronics Group.

His research interests include electromagnetic modeling, linear actuators, and electromagnetic active suspension systems.

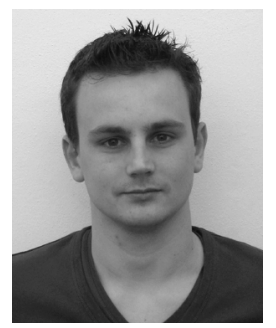

Tom P. J. van der Sande was born in Boxtel, The Netherlands, in 1986. He received the B.Sc. degree in mechanical engineering and the M.Sc. degree in automotive technology from Eindhoven University of Technology, Eindhoven, The Netherlands. He is currently working toward the Ph.D. degree with the Department of Electrical Engineering, Eindhoven University of Technology, with the Dynamics and Control Group.

His research interests include the control of vehicle dynamics.

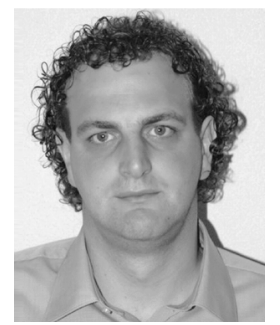

Johannes J. H. Paulides (M'06) was born in Waalwijk, The Netherlands, in 1976. He received the B.Eng. degree from the Technische Hogeschool's-Hertogenbosch, The Netherlands, in 1998 and the M.Phil. and Ph.D. degrees in electrical and electronics engineering from the University of Sheffield, Sheffield, U.K., in 2000 and 2005, respectively.

Since 2005, he has been a Research Associate with the Department of Electrical Engineering, Eindhoven University of Technology, Eindhoven, The Netherlands. He is also currently the Director of Paulides BV and Advanced Electromagnetics BV, which is a Netherlands-based small and medium enterprise that produces electrical machines and prototype electromagnetic devices. His research interests include electrical machines, in particular linear and rotating permanent-magnet excited machines for automotive and high-precision applications.

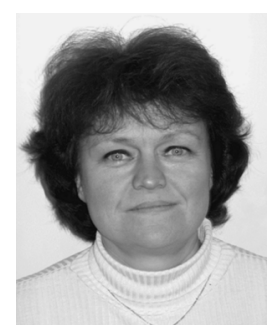

Elena A. Lomonova (M'04-SM'07-F' 10) was born in Moscow, Russia. She received the M.Sc. ( cum laude) and Ph.D. (cum laude) degrees in electromechanical engineering from the Moscow State Aviation Institute, in 1982 and 1993, respectively.

She is currently a Professor with the Department of Electrical Engineering, Eindhoven University of Technology, Eindhoven, The Netherlands. She has worked on electromechanical actuator design, optimization, and the development of advanced mechatronics systems. 